\title{
Crystal structure of an anti-interleukin-2 monoclonal antibody Fab complexed with an antigenic nonapeptide
}

\author{
PAVEL V. AFONIN, ${ }^{1}$ ANDREY V. FOKIN, ${ }^{1}$ IGOR N. TSYGANNIK, ${ }^{1}$ \\ IRINA YU. MIKHAILOVA, ${ }^{1}$ LYUDMILA V. ONOPRIENKO, ${ }^{1}$ INNA I. MIKHALEVA, ${ }^{1}$ \\ VADIM T. IVANOV,${ }^{1}$ TAT'YANA YU. MAREEVA, ${ }^{1}$ VLADIMIR A. NESMEYANOV,${ }^{1}$ \\ NAIYIN LI ${ }^{2}$ WALTER A. PANGBORN,${ }^{2}$ WILLIAM L. DUAX,${ }^{2,3}$ AND \\ VLADIMIR Z. PLETNEV ${ }^{1}$ \\ ${ }^{1}$ Shemyakin-Ovchinnikov Institute of Bioorganic Chemistry, Russian Academy of Sciences, 117871 Moscow, Russia \\ ${ }^{2}$ Hauptman-Woodward Medical Research Institute, Buffalo, New York 14203, USA
}

(Received January 22, 2001; Final Revision April 23, 2001; Accepted May 1, 2001)

\begin{abstract}
The three-dimensional structure of the Fab fragment of a monoclonal antibody (LNKB-2) to human interleukin-2 (IL-2) complexed with a synthetic antigenic nonapeptide, Ac-Lys-Pro-Leu-Glu-Glu-Val-Leu-AsnLeu-OMe, has been determined at $3.0 \AA$ resolution. In the structure, four out of the six hypervariable loops of the Fab (complementarity determining regions [CDRs] L1, H1, H2, and H3) are involved in peptide association through hydrogen bonding, salt bridge formation, and hydrophobic interactions. The Tyr residues in the Fab antigen binding site play a major role in antigen-antibody recognition. The structures of the complexed and uncomplexed Fab were compared. In the antigen binding site the CDR-L1 loop of the antibody shows the largest structural changes upon peptide binding. The peptide adopts a mostly $\alpha$-helical conformation similar to that in the epitope fragment $64-72$ of the IL-2 antigen. The side chains of residues Leu 66, Val 69, and Leu 70, which are shielded internally in the IL-2 structure, are involved in interactions with the Fab in the complex studied. This indicates that antibody-antigen complexation involves a significant rearrangement of the epitope-containing region of the IL-2 with retention of the $\alpha$-helical character of the epitope fragment.
\end{abstract}

Keywords: Monoclonal antibody; Fab-antigen binding fragment; interleukin-2 antigen; antibody-antigen interaction; three-dimensional structure; X-ray analysis

Monoclonal antibodies are used widely in biomedical research because of their stereochemical complementarity to specific antigens. Determination of the structural basis of antibody-antigen specificity is important to understanding the mechanism of immune recognition and the rational design of pharmacological agents, synthetic vaccines, and antibodies with novel selectivities. Some aspects of the recognition process remain unclear. The determination of the

Reprint requests to: William L. Duax, Hauptman-Woodward Medical Research Institute, 73 High St., Buffalo, New York 14203, USA; e-mail: duax@hwi.buffalo.edu; fax: (716) 852-6086.

Article and publication are at http://www.proteinscience.org/cgi/doi/ 10.1101/ps.3101.
X-ray crystal structures of a number of unliganded antibodies, isolated antigens, and their complexes has advanced understanding of the nature of antibody-protein-antigen interactions (see selected references: Padlan 1990; Wilson et al. 1991; Rini et al. 1992; Arevalo et al. 1993; Bentley 1994; Dougall et al. 1994; Stanfield and Wilson 1994; Fields et al. 1996; Jones and Thornton 1996; Braden et al. 1998; Boehm et al. 1999; Conte et al. 1999; James et al. 1999; van den Elsen et al. 1999; Decanniere et al. 2000; Fleury et al. 2000; Graille et al. 2000; Guddat et al. 2000; Li et al. 2000). Such studies have shown that in addition to hydrogen bonds, salt bridges, and van der Waals contacts having a critical role in recognition, conformational changes induced in the antibody, in the antigen, or both may be required. 
A murine antibody LNKB-2 was produced against human interleukin-2 (IL-2). The antibody is an IgG1 isotype and binds IL-2 with high affinity $\left(\mathrm{K}_{\mathrm{aff}} \sim 3 \times 10^{8} / \mathrm{M}\right.$; Lunev et al. 1990). The epitope of this antibody is located at the 59-72 site of the IL-2 sequence (Onoprienko et al. 1989; Lunev et al. 1990). IL-2 is one of the main cytokines responsible for growth and differentiation of activated T- and B-lymphocytes and is considered to be a promising agent for treatment of secondary immunodeficiencies and cancer (Smith $1988,1990,1992)$. No IL-2 peptide fragment found thus far is capable of reproducing full-scale IL-2 growth-promoting activity. However, peptides corresponding to epitope fragments 59-72 and 62-72 were shown to stimulate liver regeneration and repair after toxic injury or partial hepatectomy and were found to have potential for treatment of hepatitis, liver cirrhosis, and burns (Onoprienko et al. 1996a). The mechanism of action of these peptides appears to involve stimulation of macrophage growth-promoting activity. Nothing is known about the receptor molecule for these peptides. If the LNKB-2 antibody and the peptide receptor recognize the 59-72 fragment of IL-2 in a similar way, it may be possible to use information derived from the structural studies of antigen-antibody complexes to design peptide analogs with higher affinity for both the antibody and the receptor, which in turn could result in enhanced biological activity. Therefore, information concerning the structural organization of both the uncomplexed and complexed LNKB-2 could be important for understanding the structural basis of the binding process and for designing new biomedically potent peptide analogs.

Our determination of the $2.2-\AA$ resolution crystal structure of the unliganded Fab of LNKB-2 provided detailed information concerning the antibody binding site (Fokin et al. 2000). In this paper we present the results of an X-ray study of the crystal structure of Fab-LNKB-2 in complex with the antigenic nonapeptide Ac-Lys-Pro-Leu-Glu-GluVal-Leu-Asn-Leu-OMe, an analog of the IL-2 epitope fragment 64-72.

\section{Results and Discussion}

\section{Overall structure}

The overall conformation of the Fab-LNKB-2 antibody is similar in the uncomplexed (Fokin et al. 2000) and complexed structures with a root mean square deviation (RMSD) of $0.55 \AA$ for 425 of the total $439 \mathrm{C}^{\alpha}$ atoms. Those excluded because of weak electron density are identified in the Materials and Methods section. The variable $\left(\mathrm{V}_{\mathrm{L}}\right.$ and $\left.\mathrm{V}_{\mathrm{H}}\right)$ and constant $\left(\mathrm{C}_{\mathrm{L}}\right.$ and $\left.\mathrm{C}_{\mathrm{H}} 1\right)$ domains of the light and heavy chains are similarly arranged with an "elbow" angle of $\sim 145^{\circ}$ in both structures. The polypeptide chain in each domain adopts the "immunoglobulin greek key" fold (Richardson 1981), characterized by a sandwich-type structure built from two twisted antiparallel $\beta$-sheets. The surface of the Fab binding pocket is lined by the residues from six hypervariable loops, or complementarity determining regions (CDRs), of the variable domains (Table 1) that include eight Tyr residues. Statistical analysis (Padlan 1990) has shown that tyrosines are three times more likely to be found in CDRs than in the framework of the variable domains. They present large surface areas for interaction with ligands and can form hydrogen bonds through either the $\pi$ cloud of their aromatic rings (Levitt and Perutz 1988) or their $\mathrm{OH}$ groups. According to standard nomenclature (Chothia et al. 1989), five of the CDRs in the LNKB-2 antibody can be assigned to known canonical structural classes (Table 1). The hypervariable loop H3 in the observed structure remains unassigned. In Fab structures this loop shows extensive structural diversity (Morea et al. 1997; Decanniere et al. 2000). The backbone trace and side chain orientations in the Fab binding site are not altered significantly upon peptide binding. In the antigen binding site the largest structural difference is in the CDR-L1 loop, for which the RMSD on $\mathrm{C}^{\alpha}$ atoms is $1.02 \AA$.

\section{Conformation of the bound nonapeptide}

Electron density in the binding site of the Fab-LNKB-2 was assigned unequivocally to the bound nonapeptide Ac-Lys 64-Pro 65-Leu 66-Glu 67-Glu 68-Val 69-Leu 70-Asn 71Leu 72-OMe. Because of the lack of density at the ends of the peptide, accurate positions for the $\mathrm{N}$-terminal acetyl group and the side chain of C-terminal residue Leu 72 could not be established with confidence. The absence of density for the C-terminal methyl group is consistent with NMR results indicating that the ester bond $\mathrm{OC}-\mathrm{OMe}$ undergoes

Table 1. Canonical classes of hypervariable loops of Fab-LNKB-2

\begin{tabular}{llclc}
\hline CDR & Fragment & $\begin{array}{c}\text { Canonical } \\
\text { class }^{\mathrm{a}}\end{array}$ & $\begin{array}{c}\text { PDB } \\
\text { ID }^{\mathrm{b}}\end{array}$ & $\begin{array}{c}\text { RMSD }^{\mathrm{c}} \\
(\AA)\end{array}$ \\
\hline L1 & L (24-34) & 4 & lrmf $^{\mathrm{d}}$ & 0.47 \\
L2 & L (50-56) & 1 & llmk $^{\mathrm{e}}$ & 0.36 \\
L3 & L (89-97) & 1 & ltet $^{\mathrm{f}}$ & 0.27 \\
H1 & H (26-33) & 2 & lbaf $^{\mathrm{g}}$ & 0.28 \\
H2 & H (52-56) & 1 & lgig & 0.17 \\
H3 & H (95-102) & - & - & - \\
\hline
\end{tabular}

(CDR) Complementarity determining regions.

${ }^{a}$ Structural classification according to Chothia et al. (1989).

${ }^{\mathrm{b}}$ Protein database codes for the basic structures presenting corresponding canonical classes.

${ }^{c}$ Root mean square deviations of $\mathrm{C}^{\circ}$-atoms of hypervariable loops of $\mathrm{Fab}$ peptide complex from those of basic structures of the same class.

dedrzejas et al. (1995).

e Perisic et al. (1994).

${ }^{f}$ Shoham et al. (1993).

g Brunger et al. (1991).

${ }^{\text {h }}$ Bizebard et al. (1994). 


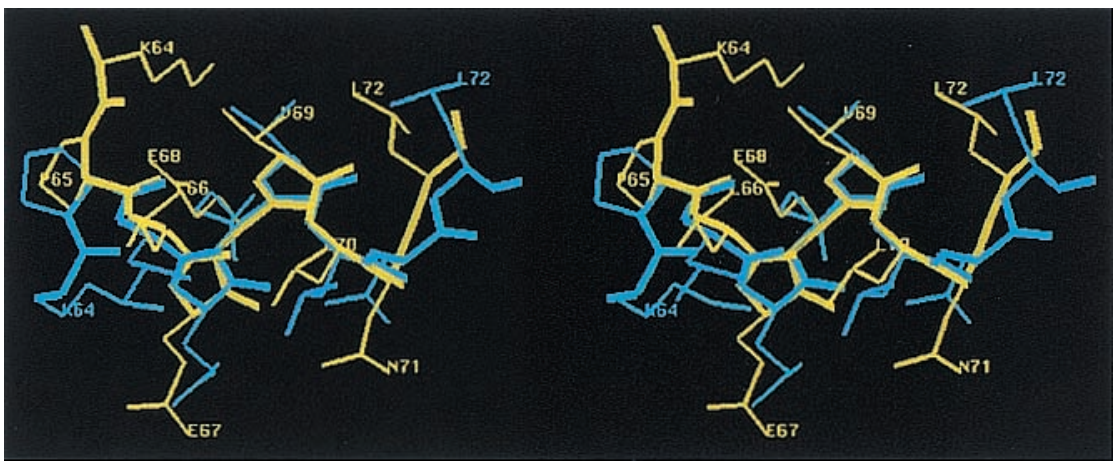

Fig. 1. A stereoview of superimposed structures of the antigenic peptide (yellow) bound to Fab and the epitope fragment (blue) of the IL-2 antigen ( $\mathrm{C}^{\alpha}$ atom positions of the conformationally similar part 66-70 were used).

hydrolysis in the presence of the antibody (Balashova et al. 1993). The conformation of the bound peptide resembles that of the corresponding epitope fragment (Fig. 1) in the crystal structure of IL-2 (Brandhuber et al. 1987). The torsional angles for the bound peptide and the epitope fragment are compared in Table 2. The epitope fragment, residues 64-72 in the IL-2 structure, is mostly $\alpha$-helical with a $3_{10}$ helical turn at the $\mathrm{C}$-terminal end. The bound peptide adopts a similar $\alpha$-helical conformation over most of the length from residues 66 to 70 (with RMSD $=0.375 \AA$ ) but shows noticeable melt of the helical regularity at residues 64 and 72. Only one previous example of an antibody-peptide complex in which the peptide adopts an $\alpha$-helical conformation has been reported (van den Elsen et al. 1999). NMR data (Balashova et al. 1993) indicate that the free peptide may adopt an irregular conformation in solution and that an $\alpha$-helical conformation is stabilized by antibody binding.

\section{Antibody-antigen interactions}

In the Fab complex the bound peptide interacts with four of the six hypervariable loops of the combined antigen binding site, L1, H2, H3, and H1 (Table 3; Figs. 2, 3). L1 plays a predominant role in peptide binding and shows the largest conformational change when compared with the unliganded Fab. In contrast, H1 plays a minor role. In total, four hydrogen bonds, two salt bridges, and 37 van der Waals contacts within $3.8 \AA$ distance contribute to the binding (see Table 3). Of nine Fab-LNKB-2 residues that interact with the peptide, the five tyrosines provide the majority of hydrogen bonds to the peptide through their $\mathrm{OH}$ groups. Four water molecules fill cavities between the interacting surfaces contributing to a hydrogen bonding network linking Leu 66(N), Glu 67(N), and Lys 64(O,N) of the peptide with Asp H97 $\left(\mathrm{O}^{\delta 2}\right)$, Gly L91(O), and Tyr H50 $\left(\mathrm{O}^{\eta}\right)$ of the $\mathrm{Fab}$ (see Table 3). The interacting surfaces of the nonapeptide and the Fab, which are shielded upon binding, have areas of 562 and $426 \AA^{2}$, respectively (for a probe size $1.4 \AA$ ). This accounts for $\sim 50 \%$ and $\sim 2 \%$ of their total accessible areas in the uncomplexed states. More extensive interface interactions with the involvement of additional CDRs may occur with larger peptides presented by the epitope fragment 5972 as well as by the entire IL-2 antigen.

The side chains of peptide residues Leu 66, Leu 70, and a part of Val 69 are buried in the Fab binding pocket and participate in van der Waals contacts with antibody resi-

Table 2. Conformational angles (grad) of the bound antigenic peptide

\begin{tabular}{|c|c|c|c|c|c|c|c|c|c|c|c|c|c|c|c|c|c|c|}
\hline \multirow[b]{2}{*}{ Angle } & \multicolumn{2}{|c|}{ Lys 64} & \multicolumn{2}{|c|}{ Pro 65} & \multicolumn{2}{|c|}{ Leu 66} & \multicolumn{2}{|c|}{ Glu 67} & \multicolumn{2}{|c|}{ Glu 68} & \multicolumn{2}{|c|}{ Val 69} & \multicolumn{2}{|c|}{ Leu 70} & \multicolumn{2}{|c|}{ Asn 71} & \multicolumn{2}{|c|}{ Leu 72} \\
\hline & $\mathrm{AP}^{\mathrm{a}}$ & $\mathrm{IL}-2^{\mathrm{b}}$ & $\mathrm{AP}$ & IL-2 & $\mathrm{AP}$ & IL-2 & $\mathrm{AP}$ & IL-2 & $\mathrm{AP}$ & IL-2 & $\mathrm{AP}$ & IL-2 & $\mathrm{AP}$ & IL-2 & $\mathrm{AP}$ & IL-2 & $\mathrm{AP}$ & IL-2 \\
\hline$\varphi$ & - & -85 & -42 & -51 & $-65^{\mathrm{c}}$ & -61 & -50 & -69 & -86 & -58 & -47 & -67 & -75 & -58 & -127 & -71 & -154 & -78 \\
\hline$\psi$ & 129 & -33 & 151 & -46 & -40 & -43 & -35 & -40 & -53 & -50 & -46 & -41 & -11 & -12 & 51 & -18 & - & -27 \\
\hline$\omega$ & 180 & 158 & 180 & 180 & 179 & -179 & 178 & 180 & 180 & 180 & -178 & 180 & 180 & 178 & -179 & 179 & - & 180 \\
\hline$\chi_{1}$ & -161 & -153 & -34 & -39 & -75 & -153 & 169 & -179 & -76 & -89 & 175 & -172 & -67 & -82 & -63 & -84 & -174 & -80 \\
\hline$x_{2}$ & 154 & -88 & 44 & 48 & 176 & -169 & 141 & -133 & -175 & -59 & - & - & 173 & -178 & -60 & -83 & 61 & -44 \\
\hline$x_{3}$ & -178 & 166 & -36 & -38 & - & - & 54 & -75 & -59 & -63 & - & - & - & - & - & - & - & - \\
\hline$\chi_{4}$ & 168 & -85 & 15 & 13 & - & - & - & - & - & - & - & - & - & - & - & - & - & - \\
\hline
\end{tabular}

a (AP) Antigenic peptide (current work).

${ }^{\mathrm{b}}$ (IL-2) Interleukin-2 (X-ray structure; Brandhuber et al. 1987).

${ }^{\mathrm{c}}$ The backbone torsional angles of the residues in the same conformational state (within $30^{\circ}$ ) are shown in bold. 
Table 3. Stabilizing interactions for the peptide binding

\begin{tabular}{|c|c|c|}
\hline Peptide & Fab & Distance $(\AA)$ \\
\hline \multicolumn{3}{|c|}{ H-bonds $(\mathrm{d}<3.4 \AA)$} \\
\hline Glu $67\left(\mathrm{O}^{81}\right)$ & Tyr L32 $\left(\mathrm{O}^{\eta}\right)\{\mathrm{L} 1\}$ & 2.73 \\
\hline Glu $68\left(\mathrm{O}^{\varepsilon 1}\right)$ & Tyr L27D $\left(\mathrm{O}^{\eta}\right)\{\mathrm{L} 1\}$ & 2.33 \\
\hline Leu $70(\mathrm{O})$ & Tyr H53 $\left(\mathrm{O}^{\eta}\right)\{\mathrm{H} 2\}$ & 2.91 \\
\hline Asn $71\left(\mathrm{~N}^{\delta 2}\right)$ & Tyr H98 $\left(\mathrm{O}^{\eta}\right)\{\mathrm{H} 3\}$ & 2.88 \\
\hline \multicolumn{3}{|c|}{ H-bonds via $\mathrm{H}_{2} \mathrm{O}$ links $(\mathrm{d}<3.4 \AA$ ̊ $)$} \\
\hline Lys $64(\mathrm{O})$ & via w1: Tyr H50 $\left(\mathrm{O}^{\eta}\right)$ & - \\
\hline Leu $66(\mathrm{~N})$ & via w2: Asp H97 $\left(\mathrm{O}^{\delta 2}\right)$, Gly L91 (O) & - \\
\hline Glu $67(\mathrm{~N})$ & $\begin{array}{l}\text { via w3 \& w2: Asp H97 }\left(\mathrm{O}^{\delta 2}\right) \text {, Gly L91 } \\
\text { (O) }\end{array}$ & - \\
\hline Lys $64(\mathrm{~N})$ & via w4: Thr L92 (O) & - \\
\hline \multicolumn{3}{|c|}{ H-bonds with $\mathrm{H}_{2} \mathrm{O}(\mathrm{w} ; \mathrm{d}<3.4 \AA$ ̊ $)$} \\
\hline Lys $64(\mathrm{O})$ & w1 & 2.80 \\
\hline Leu $66(\mathrm{~N})$ & w2 & 2.96 \\
\hline Glu $67(\mathrm{~N})$ & w3 & 2.98 \\
\hline Lys $64(\mathrm{~N})$ & $w 4^{\mathrm{a}}$ & 3.65 \\
\hline \multicolumn{3}{|c|}{ Salt bridges $(\mathrm{d}<4.0 \AA ̊)$} \\
\hline Glu $67\left(\mathrm{O}^{\varepsilon 1}\right)$ & Lys L30 $\left(\mathrm{N}^{\zeta}\right)\{\mathrm{L} 1\}$ & 2.62 \\
\hline Glu $67\left(\mathrm{O}^{\varepsilon 2}\right)$ & Lys L30 $\left(\mathrm{N}^{\zeta}\right)\{\mathrm{L} 1\}$ & 2.68 \\
\hline & van der Waals contacts $(\mathrm{d}<3.8 \AA)$ & \\
\hline Pro 65 & $\begin{array}{l}\text { Tyr L27D }\{\text { L1 }\}, \text { Tyr L32 }\{\text { L1 }\} \text {, Thr L92 } \\
\quad\{\text { L3 }\}\end{array}$ & - \\
\hline Leu 66 & $\begin{array}{l}\text { Ala H34 }\{\mathrm{H} 1\}, \text { Tyr H50 }\{\mathrm{H} 2\}, \text { Asp H96 } \\
\{\mathrm{H} 3\}\end{array}$ & - \\
\hline Glu 67 & $\begin{array}{l}\text { Lys L30 \{L1\}, Tyr L32 }\{\text { L1 }\} \text {, Tyr H98 } \\
\quad\{\mathrm{H} 3\}\end{array}$ & - \\
\hline Glu 68 & Tyr L27D $\{\mathrm{L} 1\}$ & - \\
\hline Leu 70 & Tyr H53 $\{\mathrm{H} 2\}$, Asp H96 $\{\mathrm{H} 3\}$ & - \\
\hline Asn 71 & Tyr H98 $\{\mathrm{H} 3\}$ & - \\
\hline
\end{tabular}

Atoms participating in interaction are presented in round parentheses, CDRs are indicated by corresponding symbols in brackets.

${ }^{a}$ Out of chosen threshold for the H-bond length assuming solvent disorder.

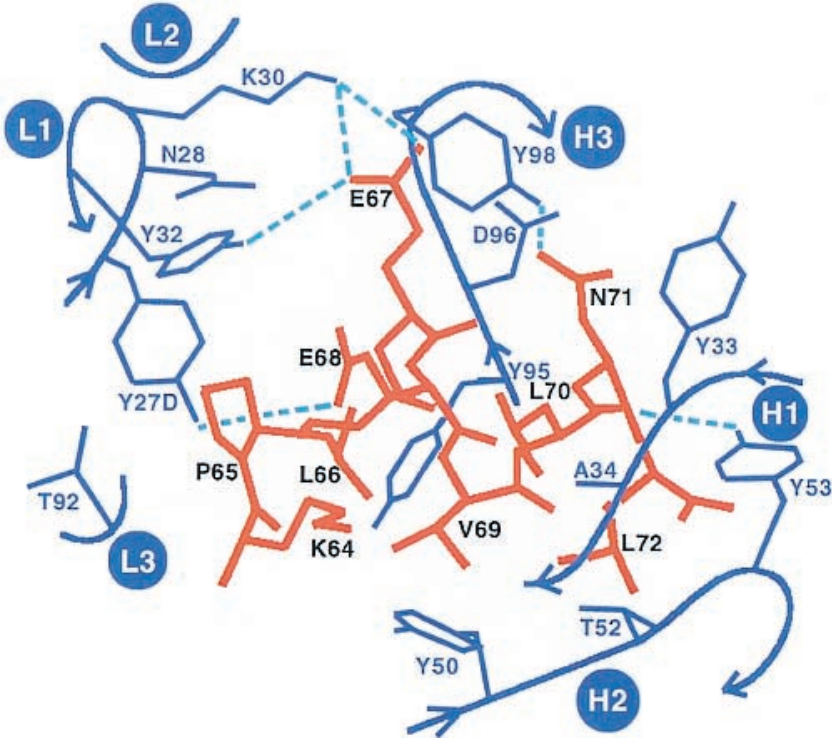

Fig. 3. The scheme of the stereochemical arrangement around the bound antigenic peptide (brown) in Fab binding pocket (blue).

dues. NMR data also indicate that these hydrophobic side chains interact with the antibody (Balashova et al. 1993). Residues Lys 64, Glu 67, Glu 68, and Asn 71 provide the major contribution to hydrogen bonding and salt bridge formation at the perimeter of the antibody binding pocket (Fig. 3; Table 3). The entire IL-2 antigen has similar structure in crystal (Brandhuber et al. 1987) and solution (Mott et al. 1995). In the IL-2 structure the corresponding epitope fragment 59-72 is a part of an amphipathic helix 54-72 that is a part of a four-helix bundle structure (Fig. 4). The hydrophobic side of the amphipathic helical epitope, composed of

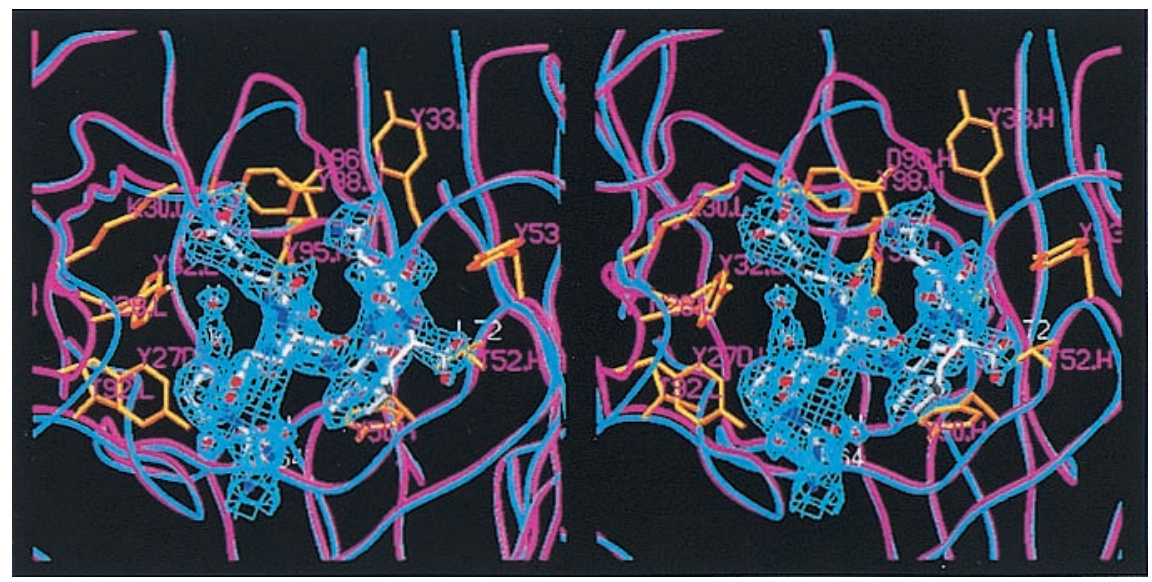

Fig. 2. A stereoview of the binding pockets of the superimposed Fab-LNKB-2 in free (blue) and complexed (magenta) forms with the side chains (brown) contacting the bound peptide (atom type). The final ( $2 \mathrm{Fo}-\mathrm{Fc}$ ) electron density map (blue) contoured at $1 \sigma_{\rho}$ is shown for the peptide and four water molecules contributing to peptide-Fab interaction. Note that the orientation of the peptide $\alpha$-helix in the antibody binding pocket is such that the side chains of leucine residues 66 and 70 are buried in the binding pocket. The figure was drawn with SETOR (Evans 1993). 


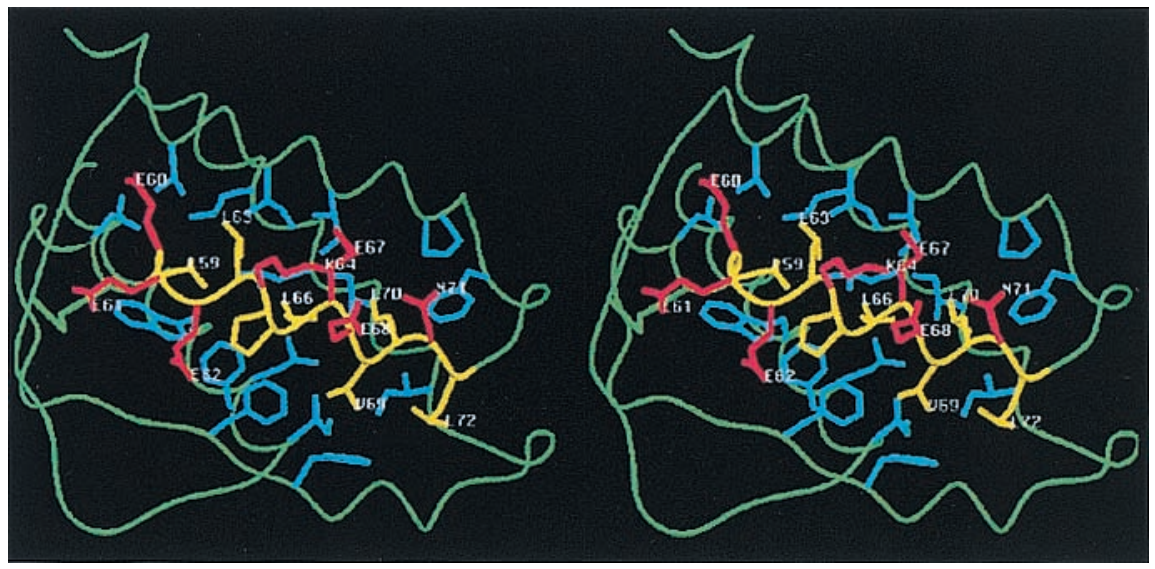

Fig. 4. A stereoview of the IL-2 structure (green) showing the side chains of the hydrophobic groove (blue) and the epitope area (yellow) with the hydrophobic (yellow) and the hydrophilic (red) side chains. Note that the side chains of leucine residues 66 and 70 are buried in the interior of the IL-2 structure. The figure was drawn with SETOR (Evans 1993).

the side chains of Leu 59, Leu 63, Leu 66, Val 69, and Leu 70 , is buried in the hydrophobic groove formed by the three other IL-2 helices in the bundle (residues 17-28, 82-93, and 114-121) and is not readily accessible to the antibody. The side chains of the residues on the hydrophilic side of the amphipathic helix (Glu 60, Glu 61, Lys 64, Glu 67, Glu 68, and Asn 71) are exposed on the surface of the antigen but are not well-suited stereochemically to the internal area of the antibody site. This could indicate a different mode of binding for the entire antigen that may involve significant induced structural rearrangement in size, shape, and charge distribution of the LNKB-2 antibody binding pocket. The transformation of the irregular state of the free peptide in solution to a regular $\alpha$-helical conformation in the antibodybound form (Balashova et al. 1993), which is similar to the conformation observed for this sequence in the IL-2 struc- ture, indicates similar binding of the peptide and the IL-2 epitope. This is indirect but strong evidence that synthetic peptide $64-72$ binds specifically. This also is supported by its affinity constant of Kaff $=8.4 \times 10^{7} / \mathrm{M}$, which is only slightly less than those of the longer synthetic IL-2 peptide $60-72\left(\mathrm{Kaff}=1.2 \times 10^{8} / \mathrm{M}\right)$ and entire antigen $(\mathrm{Kaff}=3.0$ $\left.\times 10^{8} / \mathrm{M}\right)$. Additional residues of the entire antigen probably contribute to its enhanced binding constant. For the IL-2 epitope to bind the LNKB-2 antibody in the way observed in the peptide complex reported here, the helix composed of residues 54 to 72 must move out of the hydrophobic groove of the $\alpha$-helical bundle in the IL-2 structure in such a way as to expose the hydrophobic residues for presentation to the antibody binding site. These hydrophobic residues of the antigen become buried upon antibody binding while the hydrophilic residues of the antigen provide favorable stabi-

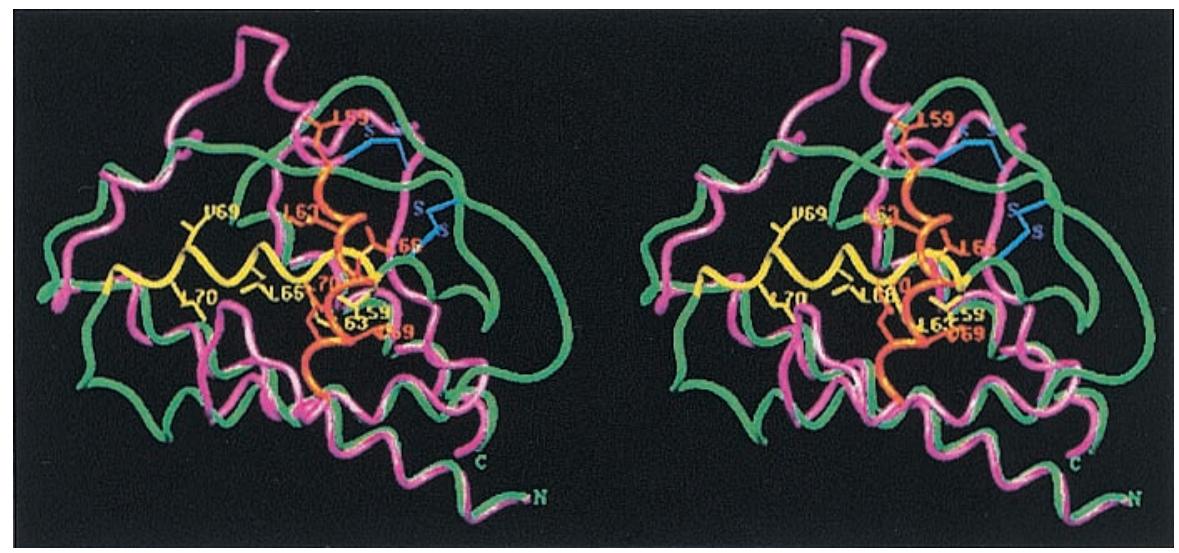

Fig. 5. A stereoview of the IL-2 structure in the native state (green) with the epitope highlighted in yellow and in the state after molecular dynamics simulation (magenta) with the epitope highlighted in brown. The hydrophobic side chains of the epitope are shown. Note that the hydrophobic edge of the epitope that is buried in the antigen in the native state (yellow segment of green strand) is exposed externally in the simulated state (brown segment of magenta strand). The figure was drawn with SETOR (Evans 1993). 
lizing contacts on the perimeter of the binding pocket (see Figs. 2, 3; Table 3). Specifically, leucine residues 66 and 70 that are buried in the IL-2 structure (yellow strand of the green molecule in Fig. 4) are seen embedded in the Fab recognition pocket in Figure 2.

A molecular dynamics simulation of residues 41-82 (which are included in the epitope containing $\alpha$-helix and the flanking regions) and loop 96-116 that lies over the N-terminal part of the helix (Fig. 5) was conducted. This simulation generated a conformational state of IL-2 in which the epitope containing $\alpha$-helix 54-72 has undergone a 5.5 - $\AA$ translational shift out of its groove in the four-helix bundle followed by approximate $180^{\circ}$ and $90^{\circ}$ rotations parallel to and perpendicular to the helix axis. In this model the epitope is more distant from the protein body than in the native structure, and the hydrophobic and hydrophilic side chains are adequately exposed to allow productive interaction with the antibody in a way that is consistent with the interaction in the crystallographically observed antibodypeptide complex; that is, leucine residues 66 and 70 that are buried in the IL-2 structure are exposed by the dynamic calculation and are available for direct interaction with the antibody binding sites. The potential energy of the simulated antibody-bound state of IL-2, based on van der Waals and electrostatic terms, is $\sim 6 \mathrm{kcal} / \mathrm{mole}$ higher than that of the native state. This higher local minimum energy state could be stabilized by interaction with antibody, providing the effective shielding of the exposed hydrophobic areas from aqueous media.

\section{Materials and methods}

\section{Crystallization and data collection}

Mouse monoclonal LNKB-2 antibodies against human interleukin-2 and corresponding Fab fragments were prepared and purified according to published procedures (Mikhailova et al. 1999). The antigenic nonapeptide Ac-Lys 64-Pro 65-Leu 66-Glu 67-Glu 68Val 69-Leu 70-Asn 71-Leu 72-OMe was synthesized by conventional methods of peptide chemistry (Onoprienko et al. 1996b). The affinity constant of the IL-2 synthetic peptide 60-72 (Kaff $\left.=1.2 \times 10^{8} / \mathrm{M}\right)$ was determined by noncompetitive enzyme immunoassay (Beatty et al. 1987). Because IL-2 peptide fragment 64-72, in contrast to fragment $60-72$, is not absorbed on a microtiter plate, its affinity constant $\left(\right.$ Kaff $\left.=8.4 \times 10^{7} / \mathrm{M}\right)$ was estimated using the method of Blondeau et al. (1978) on the basis of competitive inhibition of LNKB-2 antibody binding to IL-2 antigen by both peptides. Crystals of the complex of Fab-LNKB-2 and the synthetic peptide were grown in hanging drops at a protein concentration of 5-7 mg/mL from $12 \%-13 \%$ polyethylene glycol 4000, 12\%-13\% 2-propanol, $60 \mathrm{mM}$ sodium citrate ( $\mathrm{pH} \sim 5.6$ ). Crystal decay in the X-ray beam limited the resolution of the data. X-ray diffraction data were collected to $3.0 \AA$ on a Rigaku R-AXIS II image plate detector at ambient temperature and were processed with the software package DENZO (Otwinowski and Minor 1997). The crystallographic data are presented in Table 4.
Table 4. Refinement statistics

\begin{tabular}{|c|c|}
\hline Molecular weight $(\mathrm{kD})$ & $\sim 49$ \\
\hline Space group & $\mathrm{P} 2_{1}$ \\
\hline \multicolumn{2}{|l|}{ Unit cell parameters } \\
\hline A & 46.83 \\
\hline $\mathrm{b}$ & 72.76 \\
\hline $\mathrm{c}$ & $72.15 \AA$ \\
\hline$\beta$ & $106.98^{\circ}$ \\
\hline $\mathrm{Z}$ & 2 \\
\hline $\mathrm{V}$ & $235123 \AA^{3}$ \\
\hline Resolution $(\AA)$ & 3.0 \\
\hline Matthews coefficient $\left(\AA^{3} / \mathrm{Da}\right)$ & 2.4 \\
\hline Total reflections measured & 19271 \\
\hline Number of unique reflections $(\mathrm{F} \geq 0)$ & 9377 \\
\hline Completeness (\%) & 99.7 \\
\hline $\mathrm{R}_{\text {merge }} \mathrm{a}^{\mathrm{a}}$ & 0.112 \\
\hline \multicolumn{2}{|l|}{ Residues } \\
\hline L-chain & 219 \\
\hline H-chain & 220 \\
\hline Peptide & 9 \\
\hline \multicolumn{2}{|l|}{ Nonhydrogen atoms } \\
\hline Protein & 3380 \\
\hline Peptide & 74 \\
\hline Water & 89 \\
\hline$R_{\text {cryst }}^{\mathrm{b}}(F \geq 0)$ & 0.180 \\
\hline$R_{\text {free }}(5 \%$ data, $F \geq 0)$ & 0.263 \\
\hline \multicolumn{2}{|l|}{ Average $B$-factor $\left(\AA^{2}\right)$} \\
\hline Protein & 29.8 \\
\hline Peptide & 34.3 \\
\hline Water & 29.6 \\
\hline \multicolumn{2}{|l|}{ RMSD from ideal values } \\
\hline Bond distance $(\AA)$ & 0.007 \\
\hline Bond angle (degrees) & 1.40 \\
\hline \multicolumn{2}{|l|}{$\begin{array}{l}\text { Ramachandran plot statistics (\%) } \\
\text { for torsional angles } \varphi, \psi \\
\text { (excl. Gly and Pro) }\end{array}$} \\
\hline Most favoured regions & 82.8 \\
\hline Additionally allowed regions & 14.3 \\
\hline Generously allowed regions & 1.8 \\
\hline Disallowed regions & 1.0 \\
\hline
\end{tabular}

${ }^{a} \mathrm{R}_{\text {merge }}=\left(\Sigma_{h} \Sigma_{i} \mid \mathrm{I}_{h i}-\left\langle\mathrm{I}_{h}\right\rangle\right) /\left(\Sigma_{h} \Sigma_{i} \mathrm{I}_{h i}\right)$ where $\left\langle\mathrm{I}_{h}\right\rangle$ is the mean intensity value of I observations of symmetry-related reflections with $\mathrm{h}$ indices.

$\left.{ }^{\mathrm{b}} R_{\text {cryst }}=\left(\Sigma_{h}\left|F_{\text {obs }}\right|-\left|F_{\text {calc }}\right|\right) / \Sigma_{h}\left|F_{\text {obs }}\right|\right)$.

\section{Structure determination and crystallographic refinement}

The structure of the Fab-peptide complex was determined by the molecular replacement technique with the software package AMoRe (Navaza 1994) using the unliganded Fab crystal structure in $\mathrm{P} 22_{1} 2_{1}$ space group (Fokin et al. 2000) as a search probe and a 3.5 to $10.0-\AA$ data shell. The solution was indicated unequivocally by the correlation coefficient (C-factor) and R-factor magnitudes of 74.1 and 30.0, respectively. Several rounds of crystallographic refinement at $3.0 \AA$ implementing the slow-cooling simulated annealing protocol were performed using CNS software (Brunger et al. 1998) with manual adjustment of the model in electron density using the program CHAIN, a modified version of FRODO (Jones 1978).

The observed electron density was generally in good agreement with the known protein sequence with the exception of the $\mathrm{N}$ and 
C termini of both light and heavy chains L(213-214), H(1-2), $\mathrm{H}(229-230)$, and the fragment $\mathrm{H}(128-135)$, which had weak or discontinuous density. Difference electron density in the Fab binding site was interpreted as the antigenic peptide. Eighty-nine ordered water molecules (W) from two hydration shells characterized by electron density peaks $>1 \sigma_{\mathrm{\rho}}$ with $B$-factor values $<60 \AA^{2}$ and H-bond distances in the 2.5-3.5 $\AA$ range were incorporated into the final model. A summary of refinement is given in Table 4. The analysis of the molecular geometry of the Fab-peptide complex was performed with the WHATIF (Vriend 1990), PROCHECK (Laskowski et al. 1993), CNS (Brunger et al. 1992, 1998), and CCP4 (1994) packages. The atomic coordinates of the structure (following the numbering convention of Kabat et al. 1991) are submitted to the PDB database with RCSB and PDB ID codes RCSB011391 and 1F90, respectively.

\section{Molecular dynamics simulation}

An attempt was made to simulate possible structural changes in the epitope-containing region of IL-2 that would be consistent with the interaction mode observed in the antibody-peptide complex. The molecular dynamics simulation was performed using the X-PLOR program (Brunger et al. 1992). The X-ray structure of IL-2 (Brandhuber et al. 1987) was used as a starting model with the missing residues 98-104 from the loop area introduced in a conformation corresponding to an NMR structure determination in solution (Mott et al. 1995). The protein fragment with the epitope containing $\alpha$-helix 54-72, two flanking loops 41-53 and 73-82, and the nearby flexible loop residues $96-116$ were allowed to move freely. The $\varphi$ and $\psi$ torsional angles of the $\alpha$-helix 54-72 were restrained to values within $20^{\circ}$ of those observed in the X-ray structure. The positions of $\mathrm{C}^{\alpha}$ atoms for the rest of the IL-2 structure (6-40, 83-95, and 117-133) were restrained to X-ray positions with a force constant of $0.3 \mathrm{kcal} / \mathrm{mole}$. The structure was subjected to $200 \mathrm{ps}$ molecular dynamics process at high temperature $-1200 \mathrm{~K}$ followed by $100 \mathrm{ps}$ dynamics relaxation at room temperature $-300 \mathrm{~K}$ (timestep $=0.0005 \mathrm{ps}$ ).

\section{Acknowledgments}

This work was partly supported by the Grant 00-04-46210 from Russian Fund of Basic Research.

The publication costs of this article were defrayed in part by payment of page charges. This article must therefore be hereby marked "advertisement" in accordance with 18 USC section 1734 solely to indicate this fact.

\section{References}

Arevalo, J.H., Taussig, M.J., and Wilson, I.A. 1993. Molecular basis of crossreactivity and the limits of antibody-antigen complementarity. Nature 365: 859-863.

Balashova, T.A., Pashkov, V.S., Nolde, D.E., Onoprienko, L.V., Mikhaleva, I.I., Samohvalova, L.V., Malakhova, G.V., and Arsenev, A.S. 1993. Conformation of interleukin-2 fragment 66-72 in complex with monoclonal antibody to interleukin-2. Bioorg. Khim. (Rus.) 19: 21-31.

Beatty, J.D., Beatty, B.G., and Valahos, W.G. 1987. Measurement of monoclonal antibody affinity by non-competitive enzyme immunoassay. J. Immunol. Meth. 100: 173-179.

Bentley, G.A. 1994. A structural view of immune recognition by antibodies. Collected reports of $55^{\text {th }}$ Forum in Immunology. Res. Immunol. 145: 31-85.

Bizebard, T., Daniels, R., Kahn, R., Golinellipimpaneau, B., Skehel, J.J., and Knossow, M. 1994. Refined 3-dimensional structure of the Fab fragment of a murine IgG1, $\lambda$ antibody. Acta Crystallogr. D50: 768-770.

Blondeau, J.P., Rocher, P., and Robel, P. 1978. Competitive inhibition of spe- cific steroid-protein binding: Practical use of relative competition ratios for the derivation of equilibrium inhibition constants. Steroids 32: 563-575.

Boehm, M.K., Woof, J.M., Kerr, M.A, and Perkins, S.J. 1999. The Fab and Fc fragments of IgA1 exhibit a different arrangement from that in IgG: A study by X-ray and neutron solution scattering and homology modelling. J. Mol. Biol. 286: 1421-1447.

Braden, B.C., Goldman, E.R., Mariuzza, R.A., and Poljak, R.J. 1998. Anatomy of an antibody molecule: Structure, kinetics, thermodynamics and mutational studies of the antilysozyme antibody D1.3. Immunol. Rev. 163: 4557.

Brandhuber, B.J., Boone, T., Kenney, W.C., and McKay, D.B. 1987. Threedimensional structure of interleukin-2. Science 238: 1707-1709.

Brunger, A.T. 1992. X-PLOR (version 3.1/3.851) manual. Yale University, New Haven, CT.

Brunger, A.T., Leahy, D.J., Hynes, T.R., and Fox, R.O. 1991. 2.9 A resolution structure of an anti-dinitrophenyl-spin-label monoclonal antibody Fab fragment with bound hapten. J. Mol. Biol. 221: 239-256.

Brunger, A.T., Adams, P.D., Clore, G.M., DeLano, W.L., Gros, P., GrosseKunstleve, R.W., Jiang, J.-S., Kuszewski, J., Nilges, M., Pannu, N.S., et al. 1998. Crystallography and NMR system: A new software suite for macromolecular structure determination. Acta Crystallogr. D54: 905-921.

Chothia, C., Lesk, A.M., Tranontano, A., Levitt, M., Smith-Gill, S.J., Air, G., Sheriff, S., Padlan, E.A., Davies, D., Tulip, W.R., et al. 1989. Conformations of immunoglobulin hypervariable regions. Nature 342: 877-883.

Collaborative Computational Project, Number 4. 1994. The CCP4 suite: Programs for protein crystallography. Acta Crystallogr. D50: 760-763.

Conte, L.L., Chothia, C., and Janin, J. 1999. The atomic structure of proteinprotein recognition sites. J. Mol. Biol. 285: 2177-2198.

Decanniere, K.., Muyldermans, S., and Wyns, L. 2000. Canonical antigenbinding loop structures in immunoglobulins: More structures, more canonical classes? J. Mol. Biol. 300: 83-91.

Dougall, W.C., Peterson, N.C., and Greene, M.I. 1994. Antibody-structurebased design of pharmacological agents. Trends Biotechnol. 12: 372-379.

Evans, S.V. 1993. SETOR: Hardware-lighted three-dimensional solid model representations of macromolecules. J. Mol. Graph. 11: 134-138.

Fields, B.A., Goldbaum, F.A., Dall'Acqua, W., Malchiodi, E.L., Cauerhff, A., Schwarz, F.P., Ysern, X., Poljak, R.J., and Mariuzza, R.A. 1996. Hydrogen bonding and solvent structure in an antigen-antibody interface. Crystal structures and thermodynamic characterization of three Fv mutants complexed with lysozyme. Biochemistry 35: 15494-15503.

Fleury, D., Daniels, R.S., Skehel, J.J., Knossow, M., and Bizebard, T. 2000. Structural evidence for recognition of a single epitope by two distinct antibodies. Proteins 40: 572-578.

Fokin, A.V., Afonin, P.V., Mikhailova, I.Yu, Tsygannik, I.N., Mareeva, T.Yu, Nesmeyanov, V.A., Pangborn, W., Li, N., Duax, W., Siszak, E., et al. 2000. Three-dimensional structure of the antigen-binding fragment of monoclonal antibody to human interleukin-2 in two crystal forms at 2.2 and $2.9 \AA$ resolution. Rus. J. Bioorgan. Chem. 26: 512-519.

Graille, M., Stura, E.A., Corper, A.L., Sutton, B.J., Taussig, M.J., Charbonnier, J.B., and Silverman, G.J. 2000. Crystal structure of a Staphylococcus aureus protein A domain complexed with the Fab fragment of a human IgM antibody: Structural basis for recognition of B-cell receptors and superantigen activity. Proc. Natl. Acad. Sci. 97: 5399-5404.

Guddat, L.W., Shan, L., Broomell, C., Ramsland, P.A., Fan, Z., Anchin, J.M., Linthicum, D.S., and Edmundson, A.B. 2000. The three-dimensional structure of a complex of a murine Fab (NC10.14) with a potent sweetener (NC174): An illustration of structural diversity in antigen recognition by immunoglobulins. J. Mol. Biol. 302: 853-872.

James, L.C., Hale, G., Waldmann, H., and Bloomer, A.C. 1999. 1.9 Å structure of the therapeutic antibody CAMPATH-1H fab in complex with a synthetic peptide antigen. J. Mol. Biol. 289: 293-301.

Jedrzejas, M.J., Miglietta, J., Griffin, J.A., and Luo, M. 1995. Structure of a monoclonal anti-ICAM-1 antibody R6.5 Fab fragment at $2.8 \AA$ resolution. Acta Crystallogr. Biol. Crystallogr. D51: 380-385.

Jones, T.A. 1978. A graphics model building and refinement system for macromolecules. J. .Appl. Crystallogr. 11: 268-272.

Jones, S. and Thornton, J.M. 1996. Principles of protein-protein interactions. Proc. Natl. Acad. Sci. 93: 13-20.

Kabat, E.A., Wu, E.T., Perry, H.M., Gottesman, K.S., and Foeller, C. 1991. Sequence of proteins of immunological interests. US Department of Health and Human Service, NIH, Bethesda, MD.

Laskowski, R.A., MacArthur, M.W., Moss D.S., Thornton, J.M. 1993. PROCHECK: A programme to check the stereochemical quality of protein structures. J. Appl. Cryst. 26:283.

Levitt, M. and Perutz, M.F. 1988. Aromatic rings act as a hydrogen bond acceptors. J. Mol. Biol. 201: 751-754. 
Li, Y., Li, H., Smith-Gill, S.J., and Mariuzza, R.A. 2000. Three-dimensiona structures of the free and antigen-bound Fab from monoclonal antilysozyme antibody HyHEL-63(,). Biochemistry 39: 6296-6309.

Lunev, V.E., Lukin, Yu V., Kazennykh, N.V., Belyaev, S.V., Zubov, V.P., and Nesmeyanov, V.A. 1990. Latex-aglutination analysis of human recombinant interleukin-2 with monoclonal antibodies. Biomed. Science 1: 68-72.

Mikhailova, I.Yu, Mareeva, T.Yu, Tsigannik, I.N., Mikhaleva, I.I., Onoprienko, L.V., Vikhrov, A.A., Markvicheva, E.A., Pangborn, W., Duax, W., Nesmeyanov, V.A., et al. 1999. The preparation, crystallization and preliminary X-ray study of a FAB fragment of monoclonal antibody to human interleukin-2 and its complex with an antigenic peptide. Rus. J. Bioorgan. Chem. 25: $219-223$.

Morea, V., Tramontano, A., Rustici, M., Chothia, C., and Lesk, A.M. 1997. Antibody structure, prediction and redesign. Biophys. Chem. 68: 9-16.

Mott, H.R., Baines, B.S., Hall, R.M., Cooke, R.M., Driscoll, P.C., Weir, M.P., and Campbell, I.D. 1995. The solution structure of the F42A mutant of human interleukin 2. J. Mol. Biol. 247: 979-994.

Navaza, J. 1994. AmoRe: An automated package for molecular replacement. Acta Crystallogr. A50: 157-163.

Onoprienko, L.V., Mikhaleva, I.I., Voitenkov, B.O., Ivanov, V.T., and Okulov, VB. 1996a. Peptides with regenerative-reparative action. Patent $R U$ 2065445 C1, Bulletin of Committee of Russian Federation on Patents and Trade Marks 23.

Onoprienko, L.V., Mikhaleva, I.I., Ivanov, V.T., Voitenkov, B.O., and Okulov, V.B. 1996b. Immunomodulating properties of synthetic fragments of human interleukin 2. Rus. J. Bioorg. Chem. 22: 156-165.

Onoprienko, L.V., Mikhaleva, I.I., Lunev, V.E., Nesmeyanov, V.A., and Ivanov, V.T. 1989. Synthesis and immunogenic properties of peptides corresponding to 59-72 and 25-36 sequence of human IL-2. Bioorg. Khim. (Rus.) 15: 908-921.
Otwinowski, Z. and Minor, W. 1997. Processing of X-ray diffraction data collected in oscillation mode. Meth. Enzymol. 276: 307-326.

Padlan, E.A. 1990. On the nature of antibody combining sites: Unusual structural features that may confer on these sites an enhanced capacity for binding ligands. Proteins 7: 112-124.

Perisic, O., Webb, P.A., Holliger, P., Winter, G., and Williams, R.L. 1994 Crystal structure of a diabody, a bivalent antibody fragment. Structure 2: $1217-1226$

Richardson, J.S. 1981. The anatomy and taxonomy of protein structure. Adv. Prot. Chem. 34: 167-339.

Rini, J.M., Schulze-Gahmen, U., and Wilson, I.A. 1992. Structural evidence for induced fit as a mechanism for antibody-antigen recognition. Science 255: 959-965.

Smith, K.A. 1988. Interleukin 2. Academic Press, San Diego pp. 311-317. . 1990. Interleukin-2. Sci. Am. 262: 50-57.

- 1992. Interleukin-2. Curr. Opin. Immunol. 4: 271-276.

Shoham, M. 1993. Crystal structure of an anticholera toxin peptide complex at 2.3 Å. J .Mol. Biol. 232:1169-1175.

Stanfield, R.L. and Wilson, I.A. 1994. Antigen-induced conformational changes in antibodies: A problem for structural prediction and design. Trends Biotechnol. 12: 275-279

van den Elsen, J.M., Kuntz, D.A., Hoedemaeker, F.J., and Rose, D.R. 1999. Antibody C219 recognizes an $\alpha$-helical epitope on P-glycoprotein. Proc. Natl. Acad. Sci. 96: 13679-13684.

Vriend, G. 1990. A molecular modeling and drug design program. J. Mol. Graph. 8: 52-56.

Wilson, I.A., Stanfield, R.L., Rini, J.M., Arevalo, J.H., Schulze-Gahmen, U., Fremont, D.H., and Stura, E.A. 1991. Structural aspects of antibodies an antibody-antigen complexes. Ciba Found. Symp. 159:13-39. 